\title{
REALIDAD Y DESAFIOS DE LAS SOCIEDADES LATINOAMERICANAS
}

\section{AUSJAL \\ Asociación de Universidades Jesuitas de América Latina}

$\mathrm{E}$

I cristiano mira la realidad latinoamericana desde una perspectiva que pone en primer plano las siguientes preguntas: ¿Cuál es la condición de vida de las mayorías? ¿Los poderes, saberes y haberes predominantes en el Continente están ordenados a producir vida y a crear sociedades dignas y más justas? ¿Funcionan ellos fundamentalmente como medio a favor del hombre o más lo instrumentalizan? ¿Vivimos y somos protagonistas de una cultura abierta a Dios y abierta al hermano o va prevaleciendo con eficacia una cultura cerrada en la que hay poco lugar para la solidaridad y a la trascendencia?

Estas preguntas las hacemos hoy más que nunca mirando al Continente en su conjunto y dentro del contexto mundial que condiciona cada vez más los caminos del futuro. Se trata de una mirada selectiva para identificar desafíos, aunque muy conscientes de la complejidad de la realidad y lo improcedente de cualquier respuesta simplista.

Ante estas preguntas resaltan hechos innegables que condicionan las tareas en esta década de transición de un siglo a otro y 
ayudan a establecer algunas líneas para el quehacer universitario.

\title{
1.1. Pobreza y desarrollo
}

\begin{abstract}
$\Lambda$ mérica Latina -en su rica variedad de naciones, pueblos y Aculturas - aparece como una sociedad con sus luces sombras. Por una parte la vemos como una sociedad profundamente frustrada y deficitaria en la que se acentúan los problemas de pobreza, sana convivencia y desarrollo justo. Las carencias se reflejan en el retroceso vívido en las últimas décadas, tanto en sus problemas internos como en su lugar relativo en la sociedad de naciones.
\end{abstract}

Llevamos un largo período caracterizado por la disminución del salario real de los trabajadores y la depauperación de las clases medias. En consecuencia, la polarización social crece y cada vez hay más pobres en pobreza extrema, mientras las minorías opulentas acrecientan sus ganancias.

En la economía mundial, el peso relativo de nuestro Continente ha disminuido. En 1950 nuestros países producían el 12,42\% de las exportaciones mundiales. Para 1980 el porcentaje se redujo a $5.41 \%$ y en la llamada "década perdida" bajamos al $4 \%$.

La deuda externa de más de $\mathbf{4 3 0 . 0 0 0}$ millones de dólares, superior a las razonables capacidades de pago, pesa gravemente sobre los deficitarios presupuestos públicos, compromete el futuro de nuestros países, y no tiende a reducirse. Somos exportadores netos de capitales. En la década de los ochenta se produjo una transferencia neta al exterior de 230.000 millones de dólares; para el mismo tiempo se calcula en 700.000 millones de dólares el déficit de inversión en América Latina y el Caribe.

Por otra parte, hay también signos de cambios alentadores. Se ha logrado llegar a acuerdos pacificadores en países divididos por la guerra. El terrible mal de la inflación que en los ochenta llegó a un promedio de $500 \%$ para toda América Latina, en 1994 está por debajo del $20 \%$. Las inversiones extranjeras se han incrementado y la región ya está atrayendo 8 veces más capital por año que en los ochenta. Los índices de crecimiento del PIB (Producto Interno Bruto) son significativamente superiores a los de la década pasada. La apertura entre los propios países latinoamericanos y los pasos hacia la integración regional se reflejan en acuerdos como Mercosur, 
Pacto Andino, Mercado Común Centroamericano, G3, etc. Los acuerdos han ido acompañados por un incremento muy significativo del comercio entre nuestros países, posibilidad de una mayor unidad y poder de negociación internacional y desarrollo del sentido de identidad, y solidaridad entre pueblos que tienen tantos elementos en común.

En la última década ha habido cambios significativos políticos y de orientación económica. Desde los años ochenta se ha vivido la vuelta a la democracia en forma condicionada y limitada. Las agotadas dictaduras dieron paso a las democracias recibidas con gran esperanza de mejoras socioeconómicas y de recuperación de libertades ciudadanas. Pero las democracias volvieron atadas de pies y manos. Por un lado en muchos países pareció necesario hacer borrón y cuenta nueva de las graves violaciones de derechos humanos en los regímenes militares y por otro se heredaban pesadas cargas externas y desequilibrios macroeconómicos con alarmante déficit fiscales y altas tasas de inflación.

Los vicios clientelares e intereses creados en áreas claves de la administración pública, llevaron rápidamente a fuertes frustraciones, al desprestigio creciente tanto de los partidos tradicionales y su modo de hacer política con esquemas clientelistas y uso paternalista del Estado, como también de las duras políticas económicas. Quedaba al descubierto la ineficacia y corrupción de lo público.

Las tradicionales políticas económicas de sustitución de importaciones y las prácticas políticas habituales parecían agotadas. De esta manera en la mayoría de los países se implementaron políticas de choque y de reestructuración comunes presentadas por expertos económicos, por el Fondo Monetario Internacional (FMI), el Banco Mundial (BM) y otros organismos internacionales similares. Al mismo tiempo se simplificó la realidad social y cultural y se idealizaron recetas de corte neoliberal. Algunas de ellas parecen inevitables: apertura económica internacional y desprotección, fomento de las exportaciones no tradicionales, reducción del déficit fiscal, redimensionamiento del Estado, privatización generalizada de sus empresas y combate drástico de la inflación. Estas medidas han tenido resultados macroeconómicos positivos en muchos paí- 
ses, pero todavía los costos sociales son muy altos, como lo evidencia el hecho de que la indigencia en la última década aumentó del 19 al $22 \%$ y que la pobreza llegó al $46 \%$ de la población en América Latina.

El choque de las recetas económicas y de las políticas llamadas neoliberales con las aspiraciones populares y de la clase media ha sido duro. La actividad privada al ser sometida a la competencia internacional en unos casos dejaba al descubierto sus incapacidades e ineficiencias que habían sido disimuladas por proteccionismos y subsidios gubernamentales y en otros revelaba sus enormes posibilidades.

Si las nuevas políticas económicas no integran debidamente las políticas sociales y se mantiene un divorcio entre las aspiraciones de la población y los efectos de las duras medidas de ajuste, pueden llevar a algunos de nuestros países al borde mismo de la ingobernabilidad, generando revueltas, repetidos estallidos de violencia, y expresiones de descomposición social rayanos en la anomia, fruto de la injusticia y del malestar social. Aunque la lucha armada de base ideológica va cediendo en todas partes, aumentan estas nuevas formas de violencia.

En general el Estado y el sector público están en crisis profunda y es inaplazable su redimensionamiento y saneamiento. Al mismo tiempo, la relación entre la sociedad civil y el Estado tiene que ser redefinida y la mediación política entre la sociedad y el Estado a través de los partidos políticos requiere una profunda revisión. La sociedad civil se expresa en nuevas formas de organización y se tiende a caminar hacia una relación menos paternalista con el Estado y con más capacidad para controlarlo y utilizarlo como instrumento del bien común.

Los cambios sociopolíticos y económicos de América Latina no se pueden plantear ni aisladamente, ni ignorando los grandes cambios mundiales que estamos viviendo. Estamos inmersos cada vez más en una economía que se globaliza y permite una combinación más abierta de los factores de producción. La globalización y la apertura podrían permitir que países de América Latina, de Asia, de Africa y del Este Europeo se beneficiarán de capitales y tecnología que no poseen, si se dan ciertas realidades. Los factores de 
atracción requeridos para ello tiene mucho que ver con la estabilidad política, y con aspectos educativos, sociales y culturales. En muchos casos la asimetría existente en la economía mundial, unida a la ingenua $u$ obligada apertura de mercados trae más marginación y miseria, pues lo que los países pobres producen vale menos en el mundo y lo que su población mas necesita no es prioritario dentro de un mercado de modelo consumista y aspiraciones inducidas globalizadas por los aparatos comunicacionales y de fabricación de cultural. A su vez las grandes potencias tienden a formar bloques que se cierran de manera proteccionista cuando sienten amenazados sus productos.

La caída del muro de Berlín, pasada la primera euforia, ha demostrado que el mercado es útil económicamente, pero no hace milagros. Lejos del "fin de la utopía", se ve que los pueblos, necesitan nuevos marcos institucionales, y recuperan con fuerza potencialmente conflictiva sus identidades étnicas, religiosas y culturales y requieren amplios y novedosos esfuerzos educativos, organizativos y proyectos humanos para aunar esfuerzos en torno a metas alcanzables.

Los estados y sus rígidas fronteras en muchos casos han sido desbordados y cuestionados por unidades mayores y también por la multiplicidad de pueblos y etnias que dentro de los estados reclaman su identidad y autonomía.

Entre tanto, el hecho concreto es que el actual orden económicos mundial produce desigualdad creciente que en los países más atrasados tecnológicamente y menos competitivos provoca malestar social e inestabilidad política, hasta llegar en algunos casos a la ingobernabilidad. Así se cae en un círculo vicioso: no habrá inversiones necesarias porque no hay estabilidad política ni paz social y se vive en continua emergencia socio-política porque no hay inversiones que permitan un trabajo bien remunerado.

En 1960 el $20 \%$ más rico de los países del mundo era treinta veces más rico que el $20 \%$ más pobre. Treinta años después, en 1990 , el $20 \%$ más rico de los países era sesenta veces más rico que el $20 \%$ más pobre. Las nuevas tecnologías y las aperturas de hecho han ido acompañadas por la aparición de la neopobreza, una pobreza que no es un residuo de la tradicional pobreza y atraso ru- 
ral, sino nueva, producida por las medidas liberales que, si son unilaterales, exponen a las mayorías a un darwinismo económicosocial.

En este nuevo contexto las sociedades latinoamericanos necesitan repensar muchas cosas que eran lugares comunes y parecían obvias. Para pasar de la actual pobreza, injusticia y frustración pública a sociedades más justas y de más calidad de vida no hasta la denuncia tradicional, ni las promesas populistas de los partidos, ni las ilusiones de nuevos y globales sistemas sociales idealizados o la nueva prédica ideologizante del mercado, es necesario un incremento radical de la capacidad humana productiva y organizativa de nuestras sociedades orientada y animada por nuevos valores de solidaridad que permitan mejores posibilidades de producción de bienestar interno $y$ de negociación realista a nivel internacional.

Una clave fundamental para ello es la formación humana a todos los niveles y la generación de amplios movimientos sociales con nuevos enfoques sobre el Estado y la vida pública y sobre el hecho productivo.

No se trata de ver las cosas con fatalismo para nuestros pueblos, sino de evitar toda ingenuidad acerca de los milagros del mercado y de las promesas electoreras de corte populista y de paternalismo estatal. Precisamente las universidades deberán, convertir en eje de su estudio y formación, la creación de las condiciones para que la apertura, la globalización y el mercado sean efectivos instrumentos de producción de vida y no de muerte. Esto sólo se dará si las universidades toman decisiones lúcidas.

Por otra parte, cada vez hay más consenso en que el modelo de desarrollo económico consumista y derrochador de los países más ricos no es ni alcanzable ni sostenible para la mayoría de los pueblos de la tierra. Más bien es un modelo que despilfarra recursos naturales escasos y agotables, y amenaza con destruir el equilibrio ecológico del planeta.

El modelo económico, dejado a su implacable lógica, está también produciendo deterioro en los niveles relativos de vida de los sectores medios y de bajos ingresos en los países más desarrollados y va produciendo alarmantes índices de desempleo y millones de hombres y mujeres engrosan el ejército de la neopobreza. 
En realidad no se trata de un modelo que sea sólo materialmente insostenible, lo más dramático es que parece implantar una cultura humanamente indeseable en su consumismo individualista, en su falta de sustentación para la vida moral y la solidaridad humana, y en su cerrazón a la trascendencia y a la calidad de vida espiritual.

Estamos ante una crisis de civilización que será imposible resolverla desde el economicismo consumista reinante y que nos llama a una particular creatividad espiritual para una nueva civilización. Por eso, sería muy lamentable que las universidades latinoamericanas se limitaran a transmitir, sin espíritu crítico y sin visión ética, unas recetas de desarrollo que nos llevaran a procesos imposibles e indeseables o a difundir una ilusión de humanismo carente de verdadera trascendencia.

La tarea tiene pues dos vertientes que en momentos parecen contradictorias. Por una parte, América Latina sólo podrá recuperar el necesario bienestar social y cierto poder de negociación mundial en la medida en que elevemos nuestra capacidad productiva interna. No basta la denuncia de nuestros problemas y es un error contentamos con echar la culpa a las grandes potencias o a las empresas transnacionales, aunque haya razones para ello. Es fundamentalmente responsabilidad de nuestros países la recuperación del Estado, del sentido de lo público, de la eficacia y de la honestidad de sus servicios, el dinamismo y eficiencia de la empresa productora de los bienes y servicios que con tanta urgencia necesitamos. Es decir, necesitamos la introducción y generalización decidida de ciertos elementos de la modernidad, pero no solo. Para que ello ocurra con justicia, hace falta que se generalice socialmente la capacidad de utilizar los instrumentos de la modernidad y desarrollar mayor conciencia crítica y recuperar dimensiones humanas radicales que la modernidad ha desdeñado. Todo ello supone una verdadera revolución educativa desde el preescolar y la educación básica hasta los niveles superiores.

El reto de la competitividad y apertura de los mercados obliga a medir nuestras capacidades con estándares internacionales, dejando en evidencia que el hombre, su formación y sus capacidades de conocimiento, de ciencia, tecnología y de organización produc- 
tiva de bienes, son las claves para generar las soluciones y ocupar un lugar digno en el mundo. Esto a su vez llega a una gran valoración de la educación que no puede ser vista como medio infalible de acceso a una riqueza ya existente, sino como formación para producir la riqueza que no existe. Riqueza que no es oro ni plata, sino vida ciudadana con convivencia de calidad y con los bienes y servicios que necesitamos.

La crisis generalizada que lleva a repensar la educación, exige una vigorización de las convicciones y de las actitudes morales, una afirmación de la convivencia social con espíritu de solidaridad y democracia, pero al mismo tiempo subraya el nuevo acento de la condición de medio productivo que tiene toda educación.

$\mathrm{Si}$ no hay un sustancial incremento en las capacidades productivas propias de nuestros países, éstos se verán condenados a un permanente desencuentro entre sus necesidades, demandas y aspiraciones y lo que ellas mismas son capaces de producir como oferta. En consecuencia la violencia social y la inestabilidad política se perpetuarán.

Hay, evidentemente, una concentración mundial de capital, cuya inversión es absolutamente necesaria en nuestros países si se quiere combatir la pobreza. Pero hoy la acumulación de capital y la atracción de inversiones depende cada vez menos de la cantidad de recursos naturales y de fuerza de trabajo que tenga un país. La clave está en la acumulación tecnológica basada en la intensidad del conocimiento. Un país no se desarrolla porque tenga muchos recursos naturales y mano de obra barata, sino por el talento humano expresado en ciencia, tecnología y organización. El elemento fundamental es la capacidad del talento humano para producir valor agregado.

La desmaterialización de la producción (cada vez se requieren menos materias primas por unidad de producto), trae un debilitamiento estructural de los precios de importantes materias primas ubicadas en América Latina y se empobrecen las economías que se caracterizan por la exportación de productor primarios.

Por la automatización y robotización, el trabajo (sobre todo el poco calificado) pierde valor relativo frente al capital, tanto en los paí- 
ses desarrollados económicamente como en los subdesarrollados. Las organizaciones laborales y sus luchas se debilitan y tienen que buscar formas de acción y de negociación distintas a las tradicionales.

La revolución de las telecomunicaciones, del transporte y de la informática, transforma la gestión empresarial y refuerza la trasnacionalización de los sistemas financieros y de los sistemas de comercialización y de producción dando paso a la globalización del mercado, de tal manera que parece imposible marginarse con economías autárquicas aisladas. El poder y la autonomía económica de los estados nacionales se reduce cada vez más, tanto por esta globalización como por la creación de bloques económicos supranacionales.

A pesar de la venta ideologizada que hace la corriente neoliberal de la idea de una casi milagrosa apertura económica de fronteras, los tres grandes núcleos de poder económico Estados Unidos, Japón y Europa con Alemania a la cabeza, constituyen bloques con apertura hacia dentro y restricciones hacia afuera que tienen consecuencias todavía imprevisibles sobre América Latina y su futuro. Esto hace que los mercados sub-regionales y las tendencias integradoras de la unidad latinoamericana sean realidades cada vez más urgentes si se quiere tener más capacidad de definir su relación con los bloques económicos y de negociar sin sacrificar nuestras identidades y sin olvidar las necesidades.

Ante la necesidad de mayor y más efectiva productividad nacional quedan al descubierto las debilidades e incapacidades de la empresa privada, de la gestión pública y de la conciencia ciudadana. La retórica nacionalista y denunciadora sólo pasará al terreno de las soluciones si asume con un sano pragmatismo las tareas ineludibles que señala su denuncia. Algunas de ellas son las que siguen:

- Un incremento sustantivo de las inversiones, para lo cual es necesario un clima de paz, de estabilidad política y de naciente alivio del empobrecimiento social.

- Un nuevo pacto social entre capital, trabajo y gobierno para redefinir los objetivos y políticas nacionales, y la asignación de los recursos escasos para lograrlo. 
- El logro de un incremento sustancial de la capacidad tecnológica y organizativa en su población. Este objetivo sólo se podrá lograr con una profunda transformación del sistema educativo.

En nuestros países hay un enorme potencial humano dormido por falta de una adecuada educación. Esa es la verdadera pobreza de nuestras naciones y la potenciación educativo-organizativa de las mayorías es la clave para una sustancial elevación de su capacidad de producir soluciones a los males que actualmente la aquejan. Es necesaria una educación de calidad para toda la población y una educación íntimamente vinculada a la capacidad productiva de los bienes y servicios que el país necesita. Nos referimos a la educación de la población que no va a la universidad y también a la educación universitaria como tal.

En América Latina la riqueza y pluralidad de culturas busca ser reconocida y necesita expresarse no sólo como memoria histórica e identidad, sino también como fuerza movilizadora hacia la producción de un futuro más humano. Ello concuerda con tendencias mundiales actuales en las que cierta homogeneización de la cultura global convive (e incluso estimula por reacción) con el reavivamiento de las identidades culturales y étnicas particulares.

La América mestiza podrá dasatar sus fuerzas creativas en la medida en que acepte y asuma sus culturas de procedencia distinta y construya desde ellas y no ignorándolas o negándolas. Donde coexisten en el mismo espacio geográfico grupos con niveles socio-económicos muy distintos, si no se produce un clima cultural de apertura multiétnica, el racismo y la xenofobia se apoderan de la vida de los más privilegiados económicamente, como está ocurriendo dramáticamente en regiones "avanzadas" del mundo. En América Latina tenemos una realidad más positiva, pero si se acentúan las desigualdades rebrotarán los nacionalismos agresivos y los prejuicios de corte social y racial.

El darwismo social y el individualismo posesivo se desarrollan en el terreno económico, pero tienen su vertiente cultural que en muchos países se expresa como rechazo y opresión del indígena. Su fuerte contenido ideológico se disfraza con una pretensión de objetividad con fuerza de ley científica. Esta ideología tiene serias implicaciones morales e incluso teológicas, por tratarse en la prác- 
tica de una antropología globalizante y de una prédica salvadora del individuo sólo por su propio esfuerzo y egoísmo, al mismo tiempo que desprecia la gran variedad étnica y cultural de los hijos de Dios.

\subsection{Universidad y Sociedad}

T a reflexión sobre la universidad latinoamericana cobra matices Lespecíficos en este momento de la historia. Muy otro era el planteamiento hace cuarenta años y en las décadas siguientes. Entonces era bastante aceptada la creencia de que el problema de nuestros países era el atraso secular y la solución consistía en la modernización al estilo de los países industrializados. Estos estarían deseosos de ayudar al desarrollo y nos facilitarían recursos y asesoramiento. En 1950 ó 1960 se pensaba que la distancia entre la tradicional pobreza y atraso se iba reduciendo a medida que avanzaba el esfuerzo modernizador. $Y$ en cierto sentido así fue, pero con limitaciones que hoy están a la vista.

Parecía que la discusión sobre el desarrollo se centraba entre diversas alternativas que rivalizaban por considerarse superiores unas a otras. Unas prometían sociedades de libre empresa como la norteamericana, otras el modelo del socialismo soviético, otras modelos inéditos que evitaran los errores y limitaciones de una y otra. Pero para muchos no había duda que íbamos reduciendo el atraso, nos îbamos industrializando, mejoraban los servicios sociales y la educación generalizada haría el resto. Desde hace quince años por lo menos, los problemas y las dudas han ido creciendo. Hoy hay serios retrocesos y ninguna seguridad en los modelos propuestos, ni en los caminos. La visión que se tenía de esas décadas pasadas se vuelve más crítica, y sobre todo se ve que se trata de procesos agotados o que no responden a la nueva situación.

En esos años podía parecer evidente y simple el papel de la educación en general y de las Universidades en particular. Alfabetizar, fundar escuelas y colegios, ampliar las universidades, eran convicciones indiscutibles. En ese cuadro, la Iglesia veía la importancia de formar profesionales cristianos competentes que fueran factores de cambio. Muchas de nuestras universidades se desarrollaron en ese momento. 
En América Latina y el Caribe el esfuerzo por generalizar la educación y más específicamente, por abrir la Universidad a las mayorías, ha sido impresionante. De 1950 a 1990 se ha pasado de 267.000 estudiantes de tercer nivel a cerca de 7.000.000. Cada año egresan más de medio millón de diplomados de nivel superior. El financiamiento casi íntegro de la educación superior, por el presupuesto público, abrió las puertas de la universidad a la clase media y a los sectores populares Se incrementaron las universidades e institutos superiores y egresaron varios millones de estos centros.

Por otra parte, en esos años las universidades principales eran cajas de resonancia de los problemas nacionales, centros de debate de grandes corrientes ideológicas y focos de actividad política que en la mayoría de los casos proponían cambios radicales y populares para el país respectivo.

Hoy nos encontramos con que la educación que identificaba más universitarios con más desarrollo no ha funcionado. El papel de América Latina y de su producción en la economía mundial es muy inferior al de 1950. En esos mismos años los problemas internos no se resolvieron $y$, nuestras sociedades se hicieron cada vez más duales. Por eso, cuando se habla de universidad, ya no podemos pensar simplemente que se trata de más de lo mismo; es decir, no basta seguir expandiendo los números.

Las universidades financiadas por el presupuesto público, que felizmente permitieron el acceso popular a la educación superior, están atrapadas en muchas de las deformaciones propias de la burocracia de los organismos públicos. Su papel en el ascenso social se ha estancado e incluso retrocede. La deformación gremialista que lleva a luchar sólo por las reivindicaciones del gremio descuidando la calidad de lo que ese gremio ofrece a la sociedad, tiene bloqueadas muchas respuestas educativas. La endogamia universitaria tiende a convertir a estos centros en mundos de intereses propios dejando en un segundo plano los intereses del país. Finalmente, el sistema de gratuidad total para el estudiante y pago total por parte del presupuesto oficial se revela injusto e insostenible en el nivel de educación superior a causa de las crecientes dificultades en los ingresos fiscales y porque ese financiamiento en parte se concentra en sectores acomodados. 
De esta manera, un modelo que estuvo inspirado en la justicia social y en la apertura a todos los sectores, con frecuencia se ha convertido en un centro de poca calidad, negado a las mayorías populares que no pueden acceder a causa de la pésima educación básica y media que reciben y en una carga que no puede llevar sólo el presupuesto público. Dentro de ese panorama generalizado, los profesionales de verdadera calidad que han dedicado su vida a la Universidad, sufren injustamente desprestigio, frustración, a veces verdadera proletarización y los nuevos talentos buscan dedicarse a otras actividades. Los países tienen universidades costosas y al mismo tiempo en permanente crisis financiera. Las sociedades no reciben el "producto" final que desean, es decir, profesionales altamente cualificados con actitudes éticas insobornables y comprometidos con la solución de problemas nacionales. El aporte a los avances científicos y tecnológicos, y la investigación requerida son escasos, sobre todo si se compara con los países que están en punta y con las necesidades de nuestra realidad.

Por otra parte, en los últimos años hay un gran incremento de universidades y de institutos superiores privados, pagados por las familias de los estudiantes. Así tenemos que en América Latina, en 1960 el sector privado en educación superior representaba el $16,4 \%$ de la matrícula total y en 1985 subió al $32,6 \%$. Llama la atención el alto porcentaje en Brasil $(60,0 \%)$ y en Colombia $(60,4 \%)$.

Una buena parte de este crecimiento privado deja mucho que desear, otra parte responde a la directa necesidad de las empresas de tener gente muy cualificada y lo logran. Todas tienen la interrogante de su asequibilidad para sectores de menores ingresos. Dentro de las universidades de iniciativa no oficial están las católicas que tienen, en general, características mezcladas: no están libres de algunas de las limitaciones de universidades privadas deficientes, por ejemplo, en la investigación y en la accesibilidad, pero tienen logros significativos en la producción de profesionales cualificados y con frecuencia realizan serios esfuerzos en la formación ética, en la investigación (a pesar de las limitaciones presupuestarias) y en el compromiso social.

En el conjunto de la Universidad latinoamericana, las universidades confiadas a la Compañía con las limitaciones mencionadas- 
tienen un nivel muy aceptable, pero lo que han hecho en el pasado parece insuficiente ante las perspectivas de futuro. Incluso, no pocas veces $y$ sin pretenderlo, han formado un liderazgo carente de toda opción de inspiración cristiana aplicada a la sociedad y que ha contribuido a agravar las condiciones de injusticia y de pobreza. Por eso, a la luz de la realidad latinoamericana y mundial, está en juego la verdadera capacidad de pensar con novedad el futuro positivo de nuestras sociedades y la contribución de nuestras universidades para producirlo.

En general, la crisis de la Universidad oficial gratuita está obligando a abordar nuevos esquemas de financiamiento cuya introducción tendrá un costo político. El presupuesto estatal universitario requiere un fuerte complemento de parte de la empresa productiva pública y privada, y parece inevitable el pago parcial del costo universitario por parte de los estudiantes que puedan, cuidando, por otro lado, que el Estado garantice su entrada a la universidad a todo talento joven y con vocación, aunque carezca de recursos económicos. En varios países se va avanzando en esta dirección.

El gasto y la "productividad" universitaria requieren una profunda revisión. Sin duda alguna el mejoramiento educativo seguirá siendo un importante medio de ascenso social para quienes lo logran y la universidad debe estar abierta y ser asequible a quienes no tienen recursos económicos, pero el fin y la naturaleza de la universidad no se pueden desvirtuar reduciéndolos a simple medio de ascenso social individual o a centros de beneficencia social y con bajo aporte a la solución de problemas globales de nuestras sociedades. Los intereses endogámicos y las desviaciones gremialistas atentan contra una universidad de más calidad y más estrechamente relacionada con la solución de problemas específicos del país.

Los sistemas educativos latinoamericanos requieren una mayor diversificación de manera que no desemboquen en la universidad como única salida, ni siquiera como salida privilegiada. La vinculación de educación-producción, el aprendizaje de profesiones y oficios, son necesidades del país y de la mayoría de los jóvenes ya desde los niveles de educación media e incluso básica. La universidad debe ser mucho más selectiva exigente académicamente y, 
al mismo tiempo, sin barreras económicas para los sectores de menores recursos. Pero junto a ella debe haber una verdadera opción amplia de formación profesional y técnica no universitaria.

La Universidad, además de no formar para el desempleo, tiene que formar con mentalidad para ser creadores de fuentes de trabajo y sobre todo, para sumir la realidad del país en toda su crudeza y emprender soluciones eficaces.

La investigación de problemas específicos del país, la aplicación de soluciones adaptadas, las pasantías en empresas, y el trabajo en sectores más abandonados, son algunos de los aspectos que dan realismo y contenido social y nacional a los títulos universitarios.

La formación ética y solidaria exige no solamente estudios teóricos de ética, sino vivencias concretas de solidaridad por parte de autoridades, profesores y estudiantes.

No basta que la Universidad funcione eficientemente formando profesionales que se ubiquen exitosamente en el mercado. Hoy la Universidad requiere una mejor reflexión sobre su lugar y papel en la sociedad en este momento histórico. El humanismo que se requiere no se restringe a las carreras humanísticas, sino a todas y debe modelar todas las ciencias.

\subsection{Modernidad y Universidad}

T a Universidad es una formidable fuerza modernizadora de las $\longrightarrow$ sociedades. Si actúan sin discernimiento ni espíritu crítico, la universidad latinoamericana tiene el peligro de ignorar las trampas y ambigüedades de la modernidad que ya son más visibles en las sociedades en las que ésta se ha implantado con éxito. Por eso es necesario hacer algunas consideraciones sintéticas que contribuyan a impedir toda ingenuidad en la apreciación de la modernidad y del modelo predominante de su transmisión intelectual y de aplicación social.

El proyecto ilustrado, gestado en Europa a lo largo de lo siglos y que hizo una irrupción programática en el siglo XVIII, entrañaba una radica afirmación de la emancipación humana. La razón humana afirmaba en su ilimitada potencialidad, era elevada a la ca- 
tegoría divina como expresión de la propia divinidad deíst:, con una dinámica interna que lleva a definir el mundo y regir la vida como si Dios no existiera, o al menos, como si su eventual existencia nada tuviera que ver con lo que el hombre hace con su vida y su mundo.

El hombre estaría en sí mismo perfectamente equipado para esta aventura histórica gracias a su razón subjetiva capaz de entender y de desentrañar las leyes de la razón objetiva, ocultas en el interior de todas las cosas. El descubrimiento de esas leyes nacionales, su entendimiento y su utilización adecuada darían al hombre un poder ilimitado de dominio sobre la naturaleza (incluso su propia naturaleza humana) por medio de la gerencia y la tecnología.

Según la versión optimista de esta concepción, el hombre estaría llegando a la adultez y a la verdadera capacidad de alcanzar la felicidad y de desarrollar una conducta plenamente racional y moral, liberándose así de imposiciones extrínsecas o de mediaciones y regulaciones propias de etapas pre-científicas de la humanidad, como la religión. También las leyes racionales y ordenadoras serían una realidad en el ser humano individual y colectivo, el hombre sería capaz de conocerlas y su racionalidad le llevaría a seguirlas, produciendo así la verdadera felicidad y un orden económico, social y político, justo.

La ambigüedad humana y lo que los cristianos llamamos el indeleble sello del "pecado original", que siempre deja al hombre en la necesidad de conversión y de escogencia entre el bien y el mal, serían condiciones históricas superables en la medida en que se aplicarán las leyes racionales. El hecho de que esas leyes naturales, partieran de una matriz de individualismo posesivo o de un colectivismo economicista productor de un hombre nuevo solidario, son variantes de la misma utopía ilustrada que pretendía despojar a las superiores aspiraciones humanas de su carácter utópico al vislumbrar los modos específicos para alcanzar el paraíso en la tierra, el fin de la historia o su plenitud. También sería secundario el hecho de que el racionalismo ilustrado descansara en una visión deísta, atea o simplemente agnóstica sobre la existencia o no de un Ser Supremo distinto del hombre.

El impulso secularizador del mundo ha tenido éxito sobre todo 
en las sociedades de mayores realizaciones económicas y de más avanzada modernización. Lo que en los días turbulentos de la $\mathrm{Re}$ volución Francesa se vivió violentamente como fin de la religión cristiana para dar paso al culto a la diosa razón al Ser Supremo o a nada, parece que fue un anticipo de lo que en los dos siglos siguientes iba a vivir pacíficamente gran parte de Europa (y del mundo); incluida la perplejidad y vacío que dejó la eliminación del culto y espiritualidad cristianas a finales del siglo XVIII en las sociedad francesa.

También la tarea de la dominación de la tierra ha tenido un éxito asombroso e insospechado: los medios de información, de producción y de comunicación, han logrado cambiar la tierra. En contrapartida y a consecuencia de ese éxito, la humanidad está gravemente amenazada por la destrucción de la naturaleza, se generaliza a toda la geografía la capacidad destructiva de la industrialización avanzada y el desastre ecológico será de suma gravedad antes de muchos años si no hay cambios en el mundo. Sus recursos naturales tienen unos límites y su escasez y buena administración es uno de los mayores problemas morales actuales.

El individualismo posesivo como filosofía, y sobre todo como práctica impuesta económica y culturalmente, se va generalizando en proporción directa al avance de la modernización industrial exitosa. Este avance ha logrado increibles niveles de consumo de bienes y de servicios que inicialmente parecen satisfacer una necesidad sentida para luego producir un hastío por falta de respuesta a la fundamental identidad humana o por subordinación del hombre a la dinámica económica.

Lejos de lograr con ello un equilibrio de justicia y de convivencia en las sociedades y entre los pueblos, se ha impuesto un duro darwinismo social. Los individuos, los pueblos y los continentes están sometidos a una feroz competencia en la que la mayoría son perdedores frente a una minoría ganadora que concentra más y más opulencia, poder económico y poder político. El dominio de la naturaleza se prolonga en una ilimitada y sofisticada capacidad de dominio sobre los seres humanos. La aspiración de que todos sean ganadores es una posibilidad, pero todavía está lejos de se una realidad mundial. 
Los poderes, y sobre todo los mecanismos de participación política tradicionales han sido sobrepasados o simplemente puestos al servicio de otros poderes económicos y comunicacionales mayores. Así los estados nacionales, los poderes legislativos, ejecutivos y judiciales, los partidos políticos y los sindicatos han perdido gran parte de su fuerza y de su sentido tradicional y en consecuencia pierden el apoyo de los ciudadanos que tratan de buscar otras formas más directas que representen sus intereses.

La globalización del mercado es un hecho que conlleva cierta globalización cultural y cierta nivelación de aspiraciones, necesidades y gustos. A medida que se avanza en esta línea se van produciendo las reacciones concomitantes que buscan afirmar las especificidades étnicas y preservar identidades amenazadas por el gran mercado del universo donde sólo cuentan los pueblos y las personas por su capacidad solvente de consumo y por su capacidad de producción para incrementar su poder de compra.

El pragmatismo secularizante desdeña la dimensión trascendental y de hecho quita las bases religiosas y éticas a grupos que antes se orientaban por valores tradicionales. La crisis por ese pragmatismo hedonista llega a privar del sentido mismo de la moralidad hasta aceptar como bueno lo que es útil y rentable.

Las instituciones como el Estado, la familia y la Iglesia, que encarnaban la autoridad y eran instancias que inculcaban el deber ser, entran en crisis. En consecuencia se reduce drásticamente su tradicional capacidad modeladora de la vida social y su transmisión efectiva de valores. En su lugar los medios masivos de comunicación social, dirigidos por un sentido economicista y de ganancia de "rating", modelan más efectivamente la conducta y transmiten los símbolos de éxito y de prestigo social.

No se trata aquí de minimizar los logros de esta cultura y los éxitos científico-tecnológicos y humanos de la modernidad. Se pueden señalar numerosas realidades antihumanas del pasado que han sido superadas gracias a este formidable proyecto histórico ilustrado. El problema se encuentra en que no estamos escogiendo entre sociedades del siglo XVIII y las del siglo XXI. Vamos a estas últimas con numerosos y graves problemas de sentido y de calidad humana de vida producidos en buena parte a causa de los 
éxitos de un tipo de cultura, de ciencia, de tecnología y de economía que han modelado física y espiritualmente toda la atmósfera. Así los problemas no son premodernos, sino postmodernos; incluso en América Latina.

De acuerdo a su propia inercia, la Universidad tiende a reproducir, reforzar y transmitir esa cultura y esa ciencia con las cuales la vida humana va perdiendo calidad. El joven de hoy por un lado aprende en la Universidad a ser soldado competente y exitoso en esta guerra que ya no es unilateralmente guerra contra todo lo antihumano que hay en el subdesarrollo racional e industrial. Por el contrario, también es soldado portador de una guerra antihumana en muchos y graves aspectos, que trae la implantación del desarrollo economicista y secularista.

El joven también percibe - sin teorizar mucho- la mutilación humana del triunfante racionalismo y economicismo y se asfixia por falta de oxígeno espiritual que impone un humanismo cerrado a los otros y al Otro. De ahí la búsqueda de nuevas experiencias religiosas y espirituales. Asímismo, empieza a intuir con claridad creciente la amenaza humana que entraña la dominación de la naturaleza sin freno ni contrapartida en la dimensión dialogal y contemplativa de la relación del hombre con el resto de la creación. La ecología está en el centro de las decisiones morales de estos años pues la casa humana está en peligro.

Por un lado, el desarrollo ha ampliado las posibilidades del individuo y su ámbito de libertad. Pero al mismo tiempo se trata de una libertad condicionada y sutilmente modelada por las grandes empresas productoras de formas de llenar el tiempo de ocio, los vacíos interiores y las miserias del individualismo solitario. Las empresas del tiempo libre y de la diversión, del culto del cuerpo y los fabricantes de modas van llevando las oleadas humanas en una u otra dirección, imponiendo sus valores, gustos y formas de sentir.

Junto a ello, y a veces en las mismas personas, tenemos la neopobreza de los hambrientos y marginados en las sociedades más opulentas y de manera más generalizada y dramática en las naciones y pueblos de Asia, de Africa y de América que constituyen más de tres cuartas partes de la humanidad subordinada para 
los cuales el modelo dominante de desarrollo mundial ni es posible ni es deseable.

La Universidad latinoamericana participa, por un lado de los retos planteados por el éxito de la cultura del desarrollo racionalista industrial, pero al mismo tiempo tiene que responder a formidables problemas humanos socio-económicos que de manera inequívoca caracterizan la baja calidad de vida de nuestras sociedades a fines del siglo XX. Dicho de otra manera, la Universidad latinoamericana debe contribuir a que estas sociedades sean más modernas y libres y competitivas para salir de su miseria y dominación. Pero en el intento de lograrlo, deben evitar la inducción de los males y limitaciones de la cultura economicista avanzada.

Esta profunda ambigüedad que debe enfrentar la Universidad latinoamericana atraviesa también las universidades de inspiración cristiana y aquellas que han sido confiadas a la Compañía de Jesús. No hay fórmulas de solución simple para evitarla. Más bien hay que crear comunidades universitarias con verdadera hondura humana que permitan el diálogo interdisciplinario creativo y el discernimiento espiritual sobre culturas y sociedades y refuercen el papel humanizador del hombre en las mismas.

Las Universidades de inspiración cristiana necesitan desarrollar una nueva capacidad de asumir la realidad de nuestras sociedades, una capacidad de discernimiento religioso y moral capaz de animar la actividad científica y tecnológica con una orientación humanista, con sentido de justicia y solidaridad social, y una capacidad de brindar inspiración y sentido a la creatividad de las tendencias culturales nacientes. Aquí se ubica la necesidad de inculturar el Evangelio en la Universidad de hoy. 